\title{
WestVirginiaUniversity
}

THE RESEARCH REPOSITORY @ WVU

Graduate Theses, Dissertations, and Problem Reports

2004

\section{Effects of listening to music in a precompetition routine on mood and performance}

John R. Geer

West Virginia University

Follow this and additional works at: https://researchrepository.wvu.edu/etd

\section{Recommended Citation}

Geer, John R., "Effects of listening to music in a precompetition routine on mood and performance" (2004). Graduate Theses, Dissertations, and Problem Reports. 1964.

https://researchrepository.wvu.edu/etd/1964

This Thesis is protected by copyright and/or related rights. It has been brought to you by the The Research Repository @ WVU with permission from the rights-holder(s). You are free to use this Thesis in any way that is permitted by the copyright and related rights legislation that applies to your use. For other uses you must obtain permission from the rights-holder(s) directly, unless additional rights are indicated by a Creative Commons license in the record and/ or on the work itself. This Thesis has been accepted for inclusion in WVU Graduate Theses, Dissertations, and Problem Reports collection by an authorized administrator of The Research Repository @ WVU. For more information, please contact researchrepository@mail.wvu.edu. 
John R. Geer, B.A.

\author{
Thesis submitted to the \\ School of Physical Education \\ at West Virginia University in \\ partial fulfillment of the requirements \\ for the degree of
}

\author{
Master's of Science Degree \\ In \\ Physical Education
}

\author{
Andrew C. Ostrow, Ph.D., Chair \\ Samuel J. Zizzi, Ed.D. \\ Ed Jacobs, Ph.D.
}

School of Physical Education

Morgantown, WV

2004

Keywords: Precompetition Routine, Music, Mood

Positive Affect, Negative Affect, Rowing 


\begin{abstract}
Effects of Listening to Music in a Precompetition Routine on Mood and Performance

John R. Geer
\end{abstract}

Members of a Division I university women's rowing team $(n=14)$ each performed three rowing tasks under three music conditions that asked the participants to use headphones to listen to selfselected music either, 1) not at all, 2) during their precompetition routine, or 3) during the rowing task. Positive and negative affect was assessed immediately prior to and after each task. Results indicated that mood did not differ across music conditions and was not affected by current music use or skill level ( $p$ 's $>.05$ ). No significant differences in time to complete the tasks were found across the three music conditions ( $p$ 's $>.05$ ). However, a statistically significant negative correlation was found between pre-task positive affect and time under the preparation music condition ( $r=-.64, p<.05$ ), such that as positive affect before the rowing task increased, time to complete the task decreased. 


\section{Acknowledgments}

First, I would like to thank Dr. Andrew Ostrow, my thesis committee chairperson, for all of his hard work and time devoted to helping me conceptualize, perform, and write up my thesis research project. Thank you for all of your guidance and support, and for your patience in allowing me to be stubborn and work independently at times. You have challenged me to give my best effort on this project and I am proud of the work I have accomplished.

To Dr. Sam Zizzi, thank you for all the help and feedback you have provided me throughout the process of completing this project. I especially thank you for allowing me to drop by your office numerous times to bother you with questions and for sharing your knowledge of statistics, without which I may never have completed my data analysis. Your encouragement and sense of humor helped me keep this project in perspective and see it through to the end.

I would also like to thank Dr. Ed Jacobs for taking the time to be a part of my sport psychology thesis research project. Thank you offering your unique perspective and feedback on my work throughout.

Thank you to the coaches who graciously granted me access to their athletes and for their flexibility and support in helping me conduct my thesis research. Thank you also to the women who participated in my study for volunteering to perform extra erg tests during their regular training. Your hard work and effort are greatly appreciated.

And finally, I would like to thank the graduate students in the West Virginia University Sport \& Exercise Psychology doctorate program for supporting me in my struggles to complete this thesis project and for providing me with encouragement throughout. 
Table of Contents

Introduction $\quad 1$

$\begin{array}{ll}\text { Method } & 8\end{array}$

$\begin{array}{ll}\text { Participants } & 8\end{array}$

Pilot Research $\quad 9$

$\begin{array}{ll}\text { Instrument } & 10\end{array}$

$\begin{array}{ll}\text { Procedures } & 11\end{array}$

Hypotheses $\quad 13$

$\begin{array}{ll}\text { Results } & 15\end{array}$

Positive Affect (PA) and Negative Affect (NA) 15

Performance $\quad 16$

Discussion 16

References for Manuscript $\quad 24$

Table 1: Mean Positive (PA) and Negative Affect (NA) Scores Across Music Conditions 28

Appendices

A. Pilot Research Questionnaire 29

B. Positive and Negative Affect Schedule (PANAS) 32

C. Informed Consent $\quad 34$

D. Demographic Questionnaire $\quad 37$

Additional Tables

Table 2: Mean Performance Times (sec) Across Music Conditions 39

Table 3: Intercorrelations Between Pre- and Post-task Positive (PA) and Negative Affect (NA) and Performance Time in the No Music Group 40

Table 4: Intercorrelations Between Pre- and Post-task Positive (PA) and Negative Affect (NA) and Performance Time in the Preparation Music Group

Table 5: Intercorrelations Between Pre- and Post-task Positive (PA) and Negative Affect (NA) and Performance Time in the During Music Group 42

Selected Review of Literature $\quad 43$

Precompetition Routines $\quad 43$

Qualitative Support for Routines $\quad 45$

Purposes for Using Precompetition Routines $\quad 46$

Developing Precompetition Routines $\quad 49$

Implementing Precompetition Routines $\quad 51$

Routine Flexibility $\quad 54$

Music in Sport and Exercise $\quad 55$

Effects of Music in Sport $\quad 56$

$\begin{array}{ll}\text { Music in Preparation for Performance } & 61\end{array}$

Limitations of Music in Sport Research $\quad 64$

$\begin{array}{ll}\text { Summary } & 65\end{array}$

References for Selected Review of Literature $\quad 68$ 
List of Tables

Page \#

Table 1 - Mean Positive (PA) and Negative Affect (NA) Scores Across Music Conditions

Table 2 - Mean Performance Times (sec) Across Music Conditions

Table 3 - Intercorrelations Between Pre- and Post-task Positive (PA) and Negative Affect (NA) and Performance Time in the No Music Group

Table 4 - Intercorrelations Between Pre- and Post-task Positive (PA) and Negative Affect (NA) and Performance Time in the Preparation Music Group

Table 5 - Intercorrelations Between Pre- and Post-task Positive (PA) and Negative Affect (NA) and Performance Time in the During Music Group 


\section{Introduction}

Sport and athletics have become one of the most popular components of American culture. This is evidenced by the enormous amount of media attention devoted to the coverage of amateur and professional sport. In addition to being able to see and hear about athletic competitions, the media also gives fans a chance to observe their favorite athlete's or team's preparation for competition. Video cameras capture practice drills, teams stepping off the bus at the competition site, and intricate locker room preparations. While some of these preparations may vary, some appear to be organized into specific precompetition routines carried out prior to the beginning of each contest. Recently, it has become a common site to see athletes listening to music through headphones as part of their preparation routine. However, does the listening to music before competitions really help these athletes prepare to play a basketball game or successfully execute a snowboard jump?

Within the competitive sporting environment, coaches and sport psychology consultants are always looking to help athletes reach the highest level of performance possible. While traditional efforts placed importance on the physical skills necessary for peak performance, there has been a recent emphasis on developing various mental skills too, with the objective of using both sets of skills (i.e., physical and mental) to produce consistent, high-level performance (Williams \& Krane, 2001). Of critical importance to both coaches and athletes is the consistency of performance. Any athlete has the potential to perform at a high level on a given day, according to their athletic ability. However, rarely do we find athletes that can maintain that high level consistently over time (Weinberg \& Williams, 2001). One strategy utilized by athletes, coaches and sport psychology consultants that is theorized to help increase the 
consistency of performance is a precompetitive routine (Orlick, 1986; Taylor \& Wilson, 2002; Weinberg \& Williams, 2001).

Within the literature, precompetitive routines are defined as systematic preparation plans utilizing both physical and mental skills to prepare an athlete for competition or performance (Gould, Eklund, \& Jackson, 1992; Orlick, 1986; Orlick \& Partington, 1988; Taylor, 1995; Taylor \& Wilson, 2002; Weinberg, 1988; Weinberg \& Williams, 2001). The physical components of these routines may include standardized warm-ups (Weinberg \& Williams), checking equipment (Nideffer, 1985), and eating habits (Weinberg). From a mental standpoint, routines might include positive self-talk (Orlick), imagery (Taylor \& Wilson), relaxation exercises (Nideffer), focus and concentration skills (Weinberg), and listening to music (Thiese \& Huddleston, 1999).

The usefulness of precompetitive routines has been examined by a line of qualitative research focusing on the facilitative and debilitative factors affecting peak performance in Olympic athletes (Eklund, Gould, \& Jackson, 1993; Gould et al., 1992; Gould, Guinan, Greenleaf, Medbery, \& Peterson, 1999; Greenleaf, Gould, \& Dieffenbach, 2001; Orlick \& Partington, 1988). Interviews with these athletes sought to identify the factors they perceived to have affected their performance at either the summer or winter Olympic games. The results revealed that athletes who won medals, met expectations, or had their best matches reported that using systematic precompetitive routines was a contributing factor to their success (Eklund et al.; Gould et al.; Gould et al.; Orlick \& Partington). In contrast, non-adherence to or deviation from established routines was found to have negatively affected performance in non-medalists and athletes who failed to meet performance expectations.

Despite the association found between routine use and positive performance outcomes, many questions still surround the validity of routines. For example, do precompetitive routines 
actually lead to consistency in performance? Should all routines incorporate the same physical and mental components? Are some routine components more useful or effective than others? Unfortunately, up until this point researchers have only theorized about the possible answers to some of these questions (Taylor, 1995; Taylor \& Wilson, 2002; Weinberg \& Williams, 2001), and the effectiveness of some specific precompetitive routine components has yet to be determined.

Due to the desire to perform well in competition and win, most athletes spend countless hours practicing their skills and preparing their bodies, both physically and mentally, prior to performance. One way athletes achieve this goal, is to collaborate with coaches and/or sport psychology consultants to develop and utilize systematic precompetitive routines. To create an effective routine for an athlete, it is imperative that these coaches and sport psychology consultants be aware of the specific uses, advantages and disadvantages of routines and their components.

One of the reasons for using precompetitive routines is that they help to give athletes a sense of control over their physical environment. In general, the competitive environment for each sport is fairly standard (e.g., all basketball courts are the same length and width). Therefore, athletes have the opportunity to familiarize themselves with their physical surroundings, what takes place in this setting, and how to physically interact with the environment (Weinberg \& Williams, 2001). While this may be easily accomplished for home competition sites, it may be more difficult for away facilities that have slight variations (e.g., a larger or smaller fan seating capacity). When possible, coaches should attempt to expose their athletes to their opponents' competition sites prior to the actual event either through physical exposure or at the least through the use of videos and photographs. Being aware of and 
comfortable with the physical surroundings enables athletes the opportunity to more adequately focus their attention on their mental preparation (i.e., their self-talk, emotions, and mental images) and feel more in control of their preparation and precompetition routine (Weinberg \& Williams, 2001).

Gaining this sense of control allows athletes to limit feelings of nervousness or uncertainty that may arise from being placed in an unfamiliar environment. Therefore, another purpose of precompetitive routines is, theoretically, to help athletes increase their confidence and reduce their anxiety leading up to competition (Orlick, 1986; Taylor \& Wilson, 2002). The routines give athletes specific instructions regarding how to prepare for competition. The implementation and completion of each preparatory step of a routine gives athletes confidence in their preparation for competition. It is not unusual for athletes to become more anxious prior to competitions of greater significance (e.g., playoff games or rivalry games). Using a standardized precompetitive routine to prepare for competitions, regardless of importance, may help athletes limit unnecessary nervousness or negative thoughts, and address each competition with similar expectations for performance and success (Taylor \& Wilson, 2002).

In addition to decreasing the level of anxiety felt by athletes prior to competition, precompetitive routines can also help athletes limit the possibility of other distractions interfering with their preparation (Eklund et al., 1993). Routines establish where and how an athlete's time will be spent leading up to the time of competition. Consistently carrying out these routines may decrease the likelihood that an athlete will become involved in other potentially distracting activities and thoughts. As a result, the routines can enable athletes to gradually and progressively narrow their concentration and focus on their upcoming competition (Weinberg, 1988). 
When attempting to develop a precompetitive routine, it is important to realize that no two athletes are alike. What facilitates preparation in one athlete may have detrimental affects for another. For example, compare two athletes that want to use a precompetitive routine to regulate their intensity level before competition. One athlete may need to utilize a "psyching up" strategy as part of his/her routine to elevate intensity. However, this same strategy may not be very effective in preparing another athlete who becomes overly nervous prior to competitions and needs to use relaxation techniques to lower intensity levels.

To understand the individual preparation needs of athletes, it is useful to consider one of the mostly widely accepted theoretical frameworks within sport psychology literature: the inverted U-hypothesis (Yerkes \& Dodson, 1908). This hypothesis asserts that a relationship exists between intensity and performance, such that rises in intensity lead to increases in performance up until an optimal level (i.e., average intensity) before the continued increase in intensity begins to negatively affect performance. An extension of this hypothesis, the individual zones of optimal function (IZOF) model (Hanin, 2000), emphasizes the fact that no two athletes are alike. Whereas one athlete's IZOF may occur at low levels of intensity, another athlete’s IZOF may occur at higher levels of intensity. The specific and unique characteristics of the athlete determine his or her level of optimal intensity needed to perform successfully. Therefore, it is very important for coaches and performance enhancement consultants to keep in mind that precompetitive routines must be individualized to each athlete, even among those who may be on the same team, rather than use one general strategy across individuals (Hanin).

In addition to each athlete having unique preparation needs, different sports require different physical and psychological preparation as well. Knowledge of the specific physical and mental demands of a sport provides information to athletes as to how to focus the various aspects 
of their preparation. In particular, Taylor (1995) stressed the importance of assessing the physical, technical, and logistical requirements for each sport. Similarly, different sports may require varying levels of intensity for optimal performance (Billing, 1980). For example, compare the physical preparation necessary for two members of the same track team competing in different events (i.e., a 100-meter sprinter and a 5000-meter distance runner). The physical and mental demands of each event are very different and, subsequently, may require differing preparation strategies.

One of the components of precompetitive routines that has recently begun to receive attention is the use of music for arousal or mood regulation before performance (Gluch, 1993; Hall \& Erickson, 1995; Karageorghis \& Terry, 1997; Thiese \& Huddleston, 1999). Regulating arousal or intensity during a precompetitive routine is important to facilitate an athlete's ability to reach his or her zone of optimal functioning (Hanin, 2000). In a review of the literature on the use of music in sport, Karageorghis and Terry (1997) concluded that the research examining the effects of music on arousal and mood regulation is inconclusive. Gfeller (1988) offers a potential reason for the equivocal results, proposing that the arousing affects of music might be based on a person's ability to develop a deep, associative response to the music. When such a connection is made to the music, the person can become motivated towards physical activity. However, this response is not only attributable to the musical selection, but also to the individual differences of the athlete (e.g., culture, experiences, personality) (Lucaccini \& Kreit, 1972).

Some authors have proposed that music can have an affect on mood states, and that these mood states may then have an affect on athletic performance (Hohler, 1989; Lucaccini \& Kreit, 1972). Rejeski (1985) hypothesized about these effects using a parallel processing framework. He asserted that at low exercise levels, external stimuli, such as music, are more easily processed 
and may reduce rates of perceived exertion. However, during higher intensity exercise, physiological stimuli, such as pain and fatigue, are more likely to dominate a person's thoughts and increase rates of perceived exertion. Contrary to these hypotheses, a study examining participants' $(n=24)$ mood states during a cycle ergometry task found that listening to music at moderate and heavy cycling rates resulted in more positive mood states and lower rates of perceived exertion (Boutcher \& Trenske, 1990). Further research by Lee (as cited in Karageorghis \& Terry, 1997) found that listening to fast, upbeat music elicited significantly higher positive and significantly lower negative mood states than when listening to either slow or no music conditions.

The contradictions in the literature about the effects of music on arousal and mood are puzzling considering qualitative research in which interviews conducted with Division I collegiate athletes revealed that athletes reported the frequent use of music as a means to selfregulate arousal levels by either “psyching-up” or relaxing before competition (Gluch, 1993; Thiese \& Huddleston, 1999). Why would athletes report using a strategy that the literature reports as inconclusive? One possible answer could involve the methodological limitations under which the effects of music on arousal and mood regulation have been studied. For example, much of the research on the effects of music in sport and exercise lacks specificity regarding the methodology of the research designs used. Rarely have the authors of this research indicated important aspects of their studies such as the type of musical selections used, the intensity level of the music, the method of music delivery (headphones or speakers), the duration of listening time, and when the music is played (Karageorghis \& Terry, 1997).

To maximize the effectiveness of a precompetitive routine, it seems logical to only include components serving a specific function towards preparation for performance. Therefore, 
from a coaching or consulting standpoint, it would be useful to know if a preparation component, such as listening to music for arousal regulation, actually serves the function it is intended to serve. The primary purpose of this study was to determine if using music as part of a precompetition routine influences mood prior to and after athletic performance on a rowing task by examining both positive and negative affective states immediately before and after performance. A follow-up purpose was to evaluate if these musical influences on mood were affected by current experience with listening to music before and during rowing tasks. In addition, this study sought to examine whether changes in positive and negative affective states following the listening of music in a precompetitive routine were correlated with performance outcome, measured in time, on a rowing task. A secondary purpose for the current study was to determine if the effects of listening to music during a precompetition routine on mood varied by the rowing skill level of the participants.

\section{Method}

\section{Participants}

The volunteer participants for this study represented a convenience sample of 14 members of a Division I university women's rowing team. Members from both the varsity $(n=$ 7) and novice ( $n=7)$ skill levels of this team were used. The varsity level participants averaged 4.17 years of experience in rowing $(S D=2.51)$, while the novice level participants averaged 1.52 years of experience $(S D=1.83)$. Rowing participants were chosen due to the experimenter's access and their familiarity with completing high-intensity rowing tasks on a simulation rowing machine. 


\section{Pilot Research}

Pilot research was conducted to assess information about the use of music in preparation and competition strategies utilized by Division I women rowers, as they pertained to this study. A sample of rowers $(n=18)$, including participants of this study, completed a questionnaire (see Appendix A) asking specific questions about their use of music both before and during their normal rowing training. The overlap of participants between the pilot research and current study was not a concern because the questionnaire was not expected to alter the participants’ normal preparation and competition strategies prior to the current study. The results from the pilot questionnaire were used to confirm and solidify portions of the methodology for the current research study (e.g., the approximate length of preparation time/warm-up needed $(M=29.44$ minutes, $S D=14.64)$ and comfort with using headphones to listen to music while rowing $(M=$ 3.94 on a comfort scale ranging from 1 "very uncomfortable” to 6 "very comfortable, $S D=$ 1.86). An examination of when these rowers used music showed that music was being used in a variety of situations. For example, the rowers had used music before competitions $(n=13)$, before erg tasks $(n=12)$, during erg tasks $(n=10)$, before practices $(n=7)$, and during practices $(n=2)$ (multiple responses were accepted). This relatively high reported use of music as a preparation strategy (before erg tasks, practices, and competitions) confirms that listening to music was a component of preparation routines being used and was worthy of being evaluated to determine its effectiveness. With regard to why the rowers use music during their preparation, focus and concentration ( $n=11)$, energizing or to raise intensity $(n=10)$, and to block out distractions ( $n=7)$ were the three most cited reasons for listening to music (multiple responses were accepted). These reasons support earlier research (Gluch, 1993; Stevens and Lane, 2001) that found that athletes often cite the regulation of arousal as a reason for listening to music 
before performance. On the other hand, a small number of rowers responded that they do not use music as part of their preparation in rowing. The three most common reasons cited why they do not use music were that it was distracting $(n=3)$, it energizes them too much $(n=2)$, and that they had never thought to use music ( $n=2)$ (multiple responses were accepted).

\section{Instrument}

The Positive and Negative Affect Schedule (PANAS) (Watson, Clark, \& Tellegen, 1988) (see Appendix B) was used to assess the mood or affect in this study. The PANAS is a brief, self-administered questionnaire measuring two components of mood: positive affect (PA; 10 items) and negative affect (NA; 10 items). The developers of the PANAS classify PA as the extent to which a person feels enthusiastic, active, and alert and may be characterized by having energy, concentration, or pleasure. NA is classified as the extent to which a person feels distress and unpleasurable engagement and may be characterized by anger, guilt, fear, or nervousness (Watson, et al.). Answers are scored on a Likert-style scale with the following responses: $1=$ very slightly or not at all; 2 = a little; 3 = moderately; 4 = quite a bit; and $5=$ extremely. For this study, the time instruction of, "right now, that is, at the present moment" was used to assess the participants’ affect immediately before and after completing three rowing tasks.

The PA and NA scales have been found to have high levels of internal consistency ( $n$ 's ranging from 586 to 1,002), with coefficients (Cronbach’s alpha) ranging from .86 to .90 for PA and .84 to .87 for NA (Watson et al., 1988). Similar levels of internal consistency have been found in further psychometric evaluations of the PANAS. Melvin and Molloy (2000) reported alphas of .89 and .87 for PA and NA respectively $(n=237)$, while Molloy, Pallant, and Kantas (2001) reported alphas ranging from .88 to .90 for PA and .87 for NA $(n=670)$. In addition, neither PA nor NA appears to be affected by the variance in time instructions tested (moment, 
today, past few days, past few weeks, year, and general). Low correlations ranging from -.12 to .23 for PA and NA indicate a lack of dependence between the scales (Watson, et al.). Again, these low correlations were replicated through additional psychometric assessment and found to range from -.25 to -.29 (Melvin \& Molloy; Molloy et al.). Test-retest reliability was evaluated over an eight-week interval and coefficients of .54 for PA and .45 for NA (using the time instruction of “moment”) were found (Watson, et al.). Despite these relatively low coefficients, these results support the notion by authors' of the PANAS that even momentary mood can be an expression of a person's dispositional mood.

The convergent validity of the PANAS was tested with the Hopkins Symptom Checklist (HSCL) and the State-Trait Anxiety Inventory - State Anxiety Scale (A-State) under the time instruction of "past few weeks.” Correlations with the HSCL were -.19 for PA and .74 for NA (Watson, et al., 1988). These results support the hypothesis that negative affect is related to general distress (as measured by the HSCL). Correlations with the A-State were -.35 for PA and .51 NA (Watson, et al.). Such correlations were expected since the items present on the PANAS assess moods that are commonly associated with presence of anxiety (e.g., upset, nervous, or jittery) or its absence (e.g., calm, relaxed, or content).

\section{Procedures}

Following approval from the Institutional Review Board for the Protection of Human Subjects, participants for the study were contacted by the researcher, who had regular contact with the team as a graduate student performance enhancement consultant, and encouraged to voluntarily participate in the study. Those interested in participating attended a short introductory session that explained the extent of the study and highlighted the participants’ responsibilities for participation, including the need to complete three separate rowing erg tasks 
during normal practice times on specific dates. Participants were asked to read and sign a consent form outlining their rights as research participants (see Appendix C). Next, the participants completed a brief demographic questionnaire (see Appendix D) assessing previous experience with rowing and the current use of music in rowing. Each participant was asked to compile a music tape or CD containing 25-30 minutes of personally chosen music that was to be listened to during specific portions of the study. The experimenter encouraged the participants to choose music that had personal significance and that they believe would aid them in preparing for or completing a rowing erg task. The length of the participants' self-selected music tapes/CDs was chosen to cover the participants' normal preparation time (i.e., approximately 2030 minutes) for rowing erg tasks, as was determined from the pilot research study.

Each participant completed three high-intensity rowing erg tasks under three different music conditions during separate intervention sessions held at the beginning of regularly scheduled practice. Participants were notified in advance of the three specific session dates (scheduled approximately 4-5 days apart during their pre-season training) and asked to report to their normal indoor training facility at those times to complete a 2000-meter rowing ergometry task. These rowing tasks were used for this study because they represented performance training drills used in the participants’ regular practices.

Prior to the first session, the order in which the participants experienced the three musical conditions was randomly assigned. The music conditions included, (a) no music, (b) pre-music, and (c) during music. All three conditions permitted the participants the same amount of normal preparation time prior to the completion of the tasks. The no music group was asked to conduct their normal precompetition routine to prepare for the task without listening to music. The premusic group was asked to use headphones and a portable electronic device to listen to their 
personally chosen music tape during their normal precompetition routine to prepare for the task.

The during music group was asked to conduct their normal precompetition routine to prepare for the rowing task without listening to music, but then to listen to their personally chosen music during their completion of the task.

Following the precompetition preparation period in all three conditions (which included listening to music when assigned to the preparation music condition), all participants completed the PANAS scale immediately prior to beginning the rowing task. Once the task was finished, all participants again completed the PANAS scale within a one minute period. In each case, participants rated the twenty items as to how they felt at that moment. All the participants' times to complete the 2000-meter erg tasks were recorded.

\section{Hypotheses}

The following hypotheses were based on a review of the empirical and theoretical research related to this study and on the intuition of the experimenter. With regard to Positive Affect (PA) and Negative Affect (NA) scores across the three music conditions, it was hypothesized that, (a) the pre-music group would exhibit higher pre-test PA scores than the no music and during music groups, (b) the pre-music and during music groups would exhibit higher post-test PA scores than the no music group, (c) the pre-music group would have lower pre-test NA scores than the no music and during music groups, and (d) the pre-music and during music groups would have lower post-test NA scores than the no music group.

With respect to the interaction with previous music use, the participants were classified into two current music use groups (i.e., High and Low) based on their responses to two questions that appeared on the demographic questionnaire. The two questions used a Likert scale from 1 (Never) to 6 (Always) and asked "How often do you use music as part of your preparation before 
an erg test?” and "How often do you use music during an erg test?” A total score (ranging from 2 to 12) for each participant was calculated and a median split was used to separate high music users from low music users. It was hypothesized that, (a) the High current music use group would possess their lowest pre- and post-test PA scores and their highest pre- and post-test NA scores when assigned to the no music condition, (b) the Low current music use group would possess their highest pre- and post-test PA scores and their lowest pre- and post-test NA scores when assigned to the pre-music and during music conditions, (c) both the High current music use group and Low current music use group will possess there best performance scores (i.e., lowest times) during the pre-music and during music conditions, and (d) the Low current music use group will possess better performance scores during the no music condition than the High current music use group.

Next, it was hypothesized that a moderate negative correlation would exist between pretest PA scores and the amount of time needed to complete the erg task, such that as PA scores increased, overall time would decrease. Second, it was hypothesized that a moderate positive correlation would exist between pre-test NA scores and the amount of time needed to complete the erg task, such that as NA scores decreased, overall time would decrease.

Finally, it was hypothesized that no differences between the varsity and novice skill levels would exist for pre- and post-task PA and NA scores across the three music conditions. However, it was predicted that both the varsity and novice skill level groups would perform better (i.e., possess their best performance times) on the rowing task when assigned to the preparation music and during music conditions versus the no music condition. 


\section{Results}

Initial recruitment for the study among the varsity team members resulted in 11 participants agreeing to take part in the study. Four of these rowers did not complete the requirements of the study (due to injury and scheduling difficulties) and their data was removed from the analyses, resulting in seven varsity skill level participants. Recruitment from the novice team members initially resulted in eight potential participants. Illness prevented one of these rowers from completing the study and resulted in seven novice skill level participants whose data were available for analyses.

A median split of the 14 participants' responses (total score ranged from 2 to 12) to two questions from the demographic questionnaire evenly classified them into two current music use groups. The high current music use group $(n=7)$ contained three varsity and four novice participants (mean total score $=9.43, S D=.98$ ), while the low current music use group $(n=7)$ contained four varsity and three novice participants (mean total score $=4.14, S D=1.57$ ). Prior to the first rowing session, the participants answered a question asking, "How are you planning to use the music you have selected?” on a Likert scale from 1 (To Relax, To Calm Down) to 10 (To Energize, To Psych Up). The responses were negatively skewed towards the “energizing” end of the scale with an average response of $7.64(S D=2.24)$.

Positive Affect (PA) and Negative Affect (NA)

Separate two-way ANOVAs examining pre-task PA and NA scores revealed no statistically significant main or interaction effects between the High/Low current music use groups and the three music conditions $(p>.05)$. Likewise, no statistically significant main or interaction effects between the Varsity/Novice skill level groups and the music conditions were found using separate two-way ANOVAs with pre-task PA and NA as dependent variables ( $p$ > 
.05). Using PA and NA as dependent variables, two 2 (Music Use) x 3 (Music Condition) x 2 (Time) repeated measures ANOVAs did not produce any statistically significant main or interaction effects $(p>.05)$. Substituting the skill level groups for the music use groups, two 2 (Skill Level) x 3 (Music Condition) x 2 (Time) repeated measures ANOVAs using PA and NA as dependent variables also did not produce any statistically significant main or interaction effects $(p>.05)$

Performance

A 2 (Music Use) x 3 (Music Condition) repeated measures ANOVA did not reveal any statistically significant main or interaction effects using performance time as the dependent variable $(p>$.05). However, a 2 (Skill Level) x 3 (Music Condition) ANOVA with performance time as the dependent variable produced, as expected, one statistically significant main effect for skill level, with the varsity participants requiring significantly less time to complete the 2000meter rowing task, $F(1,12)=26.06, p<.001, \eta^{2}=.69$. No interaction effect was observed between the skill level groups and the music conditions on performance time $(p>.05)$.

Pearson correlations between pre-test PA and NA scores across the three music conditions and time to complete the erg task revealed only one statistically significant correlation between pre-test PA scores in the pre-music condition and time to complete the erg task $(r=$ $-.635, p<.05)$, such that as PA in the preparation music condition increased, time to complete the rowing task decreased. No other correlation coefficients were statistically significant ( $p$ 's > $.05)$.

\section{Discussion}

The main purpose of this study was to determine if listening to music in a precompetition routine influenced positive and negative mood states both before and after performance on a 
rowing task. Overall, the results of this study did not support the experimenter's hypotheses that listening to music during preparation would increase positive affect and decrease negative affect before the task. No significant pre-task differences in mood scores were observed when the participants were assigned to the preparation music condition versus the no and during music conditions. The analyses also failed to support hypotheses that post-task positive and negative affects scores would differ based on the three music conditions experienced by the participants. These results do not support earlier research by Boutcher and Trenske (1990) who found that listening to music during moderate and high intensities increased positive mood states.

Furthermore, it was hypothesized that the group of rowers having more current experience listening to music before and during rowing tasks would possess lower positive affect and higher negative affect when rowing in the no music condition, and those with less experience with music use would possess higher positive affect and lower negative affect when rowing in the preparation and during music conditions. Again, the results did not support these hypotheses, in that participants with high experience listening to music during rowing tasks did not differ on pre- and post-task mood scores from the participants with low music listening experience, regardless of the music conditions. An examination of the performance times of these two groups also failed to support hypotheses that the high and low music use groups would perform better in the preparation and during music conditions than in the no music condition. No differences in the participants’ performance times were found across the three music conditions and as a function of current music use. However, the use of a median split to divide the participants into two current music use groups may not have created sufficient discrimination between the groups. Participants with scores near the split value were potentially treated as 
being in different groups, despite minimal actual differences between these participants on music use.

This study also sought to examine whether the pre-task differences in positive and negative affect scores between the three music conditions were correlated with subsequent performance times on the rowing task. The results yielded one significant negative correlation between pre-task positive affect in the preparation music condition and time during that condition. According to this relationship, as the participants' pre-task positive affect increased following the listening to music in their precompetition routine, their time to complete the task decreased. This finding is interesting considering that no differences were found for pre-task positive affect between the three music conditions. Given the lack of difference for pre-task positive affect scores between the no music and preparation music conditions, it would be expected that both conditions would correlate similarly with performance times since the conditions did not differ in the manner in which the task was completed (i.e., neither condition used music during the task). Because a significant relationship was only found in the preparation music condition, it can be speculated that listening to music during a preparation routine possibly benefited the rowers in another fashion independent of mood change (e.g., limiting distracting thoughts, increasing confidence, or increasing focus and concentration).

A secondary purpose for the current study was to determine if the effect of listening to music during a precompetition routine on mood varied by the rowing skill level of the participants. The results supported the hypotheses and did not indicate a difference between the mood scores of the varsity and novice level participants across the three music conditions. However, neither skill level group differed in performance times across the three music conditions, failing to support hypotheses that both skill levels groups would possess better 
performance times when assigned to the preparation and during music conditions. A statistical check of the two groups’ performance times revealed that the two skill level groups did differ on their times to complete the rowing task, with the varsity participants performing the task significantly faster than the novice participants. This finding provides discriminant validity for the 2000-meter rowing task selected for use in this study, in that the task was able to distinguish, in terms of performance, between the varsity and novice skill level participants.

Within the present study, there are several limitations that may have contributed to the inability to detect statistically significant results. The low sample size ( $n=14)$ used could have prevented the ability to detect significant differences within the music conditions, and between music use groups and skill level groups (i.e., type II error). Using a larger sample of rowers could potentially help to address the differences, if they exist. In addition, a high degree of variability was evident among the mood scores (SDs ranging from 3.70 to 8.95 ) (see Table 1). With this increased variability, larger mean differences were necessary to achieve statistical significance. It is also possible that personality differences between the participants contributed to the increased variability in mood scores. Research has shown some personality traits, such as neuroticism, locus of control, and trait anxiety, to be correlated with precompetition levels of mood (Hassmen, Koivula, \& Hansson, 1998). Therefore, future research should be directed toward the potential role of personality trait differences (e.g., introversion/extroversion and neuroticism) in contributing to the observed variance in the mood assessments. Alternatively, the use of single-subject research designs may help to address the limitations of group research designs by enabling more intensive examination of intra-individual variation over time (Kazdin, 1982). 
Another potential limitation could have involved the lack of overall rowing experience of the participants. Researchers have studied the use of precompetition routines with elite level Olympic athletes (Eklund et al., 1993; Gould et al., 1992; Gould et al., 1999; Orlick \& Partington, 1988). However, the higher skill level participants of the current sample averaged only 4.17 years of experience $(S D=2.51)$. It is possible the participants are still in the process of developing their standardized precompetition routine and may not have been able to incorporate the use of music into their routines effectively to produce mood and performance differences.

Overall, the participants generally reported lower positive affect and higher negative affect scores across the three music conditions (see Table 1). Normative data collected during the development of the PANAS revealed mean positive and negative affect scores to be 29.7 (SD $=7.9)$ and $14.8(S D=5.4)$ respectively (Watson, et al., 1988). One reason the current sample’s mood scores may have deviated from these norms was the time of day during which the study took place. The tasks were completed during the rowers' regularly scheduled practice time early in the morning (i.e., 5:45 a.m.). It is possible this early morning time affected the participants’ mood scores prior to the beginning of the tasks, and that performing the tasks at different times of the day may yield different results for mood scores. However, this study sought to maintain ecological validity and provide support for a method of enhancing performance on 2000-meter rowing tasks used in the normal, early morning training of the participants. Another explanation for the digression away from the normative data involves the willingness of the participants to express their positive and negative affect. The participants may have been unwilling or unable to accurately express their affect due to the self-report nature of the PANAS. Perhaps self-report measures of mood should be supplemented with qualitative assessment to ensure more accurate 
representations of mood. Therefore, the PANAS may not have been the appropriate mood instrument to use for the current study.

The results of this study are also delimited to only one distance (2000-meters) of the rowing task. It is possible that this distance was not a sufficient length to detect differences between the groups and conditions. By expanding the distance of the rowing task to a longer distance, it may be possible to increase the variability of the time scores, thus making it more probable to detect significant differences. Similarly, the time needed to complete the rowing task (i.e., 7.5 - 9 minutes) may not have been of sufficient length to detect changes in mood. Previous research on the effects of music on mood found increases in positive mood following the listening to music on 18-minute cycling tasks (Boutcher \& Trenske, 1990). Being only half the length of the previous research's task, the current study’s task may not have allowed sufficient time to elapse to detect changes in mood.

Another time factor that could have affected the results of this study was the amount of time in which the rowers were allowed to listen to their music during the preparation music condition. Even though the rowers listened to music throughout their normal preparation time period (i.e., approximately 20-30 minutes), this length of time may not have been sufficient enough for the music to elicit changes in positive and negative mood. Unfortunately, previous research has provided equivocal results and offers no suggestions as to the amount of music listening time necessary to affect participants’ performance and mood (Karageorghis \& Terry, 1997).

An additional methodological limitation to this study involved the feedback the participants received during the rowing task about their performance. The rowing machine equipment allowed the rowers to monitor their current progress on the task through the use of 
second by second split times. Due to their experience with 2000-meter rowing tasks, the participants were aware of the necessary split times needed to perform at certain levels. Therefore, it is possible that the participants' performance times on the task were more influenced by their attention to maintaining split times than by the presence or absence of music or changes in their levels of positive and negative affect. Future research could address this limitation by eliminating the rowers' ability to use the split time screen. In addition, using a rowing task of unfamiliar length (e.g., 3050 meters) or that measures distance traveled instead of elapsed time may limit the influence of monitoring split times on performance. Yet, this study attempted to preserve ecological validity by using a task that is currently used as part of the rowers' regular training regimen. Examining the effects of listening to music before and during other rowing tasks may produce results that lack meaning and are not useful in helping the rowers improve the quality of their training.

Also, it was unclear to what extent the participants felt the music was useful in affecting their performance. Gfeller (1988) contended that music would only affect arousal levels if the participants were able to use the music to draw inspiration for activity or promote relaxation. Even though the majority of the participants reported an intention to use the music for energizing, it is possible that the participants were not actively using the music in an attempt to help them perform better on the task, despite the urging of the experimenter.

Precompetitive routines provide a systematic framework that helps athletes prepare consistently for competitions. In addition, these routines may help regulate the energy and mood levels of athletes to desirable levels prior to performance. This study supports previous research citing the use of music as a component of precompetitive routines that is being used by athletes to achieve an optimal state before performance (Gluch, 1993; Stevens \& Lane, 2001; Thiese \& 
Huddleston, 1999). All but one of the 14 participants reported using music to some degree during their preparation or completion of indoor rowing tasks. However, the results of the study did not find that using music in a precompetition routine affected pre- and post-task mood scores or performance on a high-energy rowing task. It is suggested that further research is needed to address the limitations of the current study. For example, using larger sample sizes, research should examine the effects of listening to preparation music on performance across varying rowing distances (e.g., 500, 2000, and 6000 meters) to determine if the musical effects are contingent upon the length of the athletic task. Furthermore, as suggested by Karageorghis and Terry (1997), it would be beneficial to determine the amount of music listening time needed to see subsequent effects on mood and performance in order to guide research methodology. It would also be useful to supplement mood and performance data with follow-up questionnaires examining the participants' perceptions of how the music affected their performance. This would allow for an examination of the benefits of music, if any, between actual and perceived performance. This further research is needed to determine and clarify the potential benefits of using music as a component of a precompetition routine before coaches and sport psychology consultants recommend its use for their athletes. 


\section{References for Manuscript}

Billing, J. (1980). An overview of task complexity. Motor Skills: Theory into practice, 4, 18-23.

Boutcher, S. H., \& Trenske, M. (1990). The effects of sensory deprivation and music on perceived exertion and affect during exercise. Journal of Sport and Exercise Psychology, 12, $167-176$.

Eklund, R. C., Gould, D., \& Jackson, S. A. (1993). Psychological foundations of Olympic wrestling excellence: Reconciling individual differences and nomothetic characterization. Journal of Applied Sport Psychology, 5, 35-47.

Gfeller, K. (1988). Musical components and styles preferred by young adults for aerobic fitness activities. Journal of Music Therapy, 25, 28-43.

Gluch, P. (1993). The use of music in preparing for sport performance. Contemporary Thought on Performance Enhancement, 2, 33-53.

Gould, D., Eklund, R. C., \& Jackson, S. A. (1992). 1988 U.S. Olympic wrestling excellence: I. Mental preparation, precompetitive cognition, and affect. The Sport Psychologist, 6, 358382.

Gould, D., Guinan, D., Greenleaf, C., Medbery, R., \& Peterson, K. (1999). Factors affecting Olympic performance: Perceptions of athletes and coaches from more and less successful teams. The Sport Psychologist, 13, 371-394.

Greenleaf, C., Gould, D., \& Diefenbach, K. (2001). Factors influencing Olympic performance: Interviews with Atlanta and Nagano U.S. Olympians. Journal of Applied Sport Psychology, 13, 154-184.

Hall, K. G., \& Erickson, B. (1995). The effects of preparatory arousal on sixty-meter dash performance. The Applied Research in Athletics and Coaching Annual, 70-79. 
Hanin, Y. L. (2000). Individual zones of optimal functioning (IZOF) model: Emotionsperformance relationships in sport. In Y. L. Hanin (Ed.), Emotions in sport (pp. 65-89). Champaign, IL: Human Kinetics.

Hassmen, P., Koivula, N., \& Hansson, T. (1998). Precompetitive mood states and performance of elite male golfers: Do trait characteristics make a difference? Perceptual and Motor Skills, 86, 1443-1457.

Hohler, V. (1989). Sport and music. Sport Science Review, 12, 41-44.

Karageorghis, C. I., \& Terry, P. C. (1997). The psychophysical effects of music in sport and exercise: A review. Journal of Sport Behavior, 20, 54-68.

Kazdin, A. E. (1982). Single-case research designs: Methods for clinical and applied settings. New York: Oxford University Press, Inc.

Lucaccini, L. F., \& Kreit, L. H. (1972). Music. In W. P. Morgan (Ed.), Ergogenic aids and muscular performance (pp. 235-262). New York: Academic Press.

Melvin, G. A., \& Molloy, G. N. (2000). Some psychometric properties of the positive and negative affect schedule among Australian youth. Psychological Reports, 86, 1209-1212.

Molloy, G. N., Pallant, J. F., \& Kantas, A. (2001). A psychometric comparison of the positive and negative affect schedule across age and sex. Psychological Reports, 88, 861-862.

Nideffer, R. M. (1985). Athletes’ guide to mental training. Champaign, IL: Human Kinetics.

Orlick, T. (1986). Psyching for sport: Mental training for athletes. Champaign, IL: Leisure Press.

Orlick, T., \& Partington, J. (1988). Mental links to excellence. The Sport Psychologist, 2, 105130. 
Rejeski, W. J. (1985). Perceived exertion: an active or passive process? Journal of Sport Psychology, 7, 371-378.

Stevens, M. J., \& Lane, A. M. (2001, December). Mood-regulating strategies used by athletes. Athletic Insight: The online journal of sport psychology, 3. Retrieved March, 26, 2003, from http://www.athleticinsight.com/Vol3Iss3/MoodRegulation.htm.

Taylor, J. (1995). A conceptual model for integrating athletes' needs and sport demands in the development of competitive mental preparation strategies. The Sport Psychologist, 9, $339-357$.

Taylor, J., \& Wilson, G. S. (2002). Intensity regulation and sport performance. In J. L. Van Raalte \& B. W. Brewer (Eds.), Exploring sport and exercise psychology (pp. 99-130). Washington, DC: American Psychological Association.

Thiese, K. E., \& Huddleston, S. (1999). The use of psychological skills by female collegiate swimmers. Journal of Sport Behavior, 22, 602-610.

Watson, D., Clark, L. A., \& Tellegen, A. (1988). Development and validation of brief measures of positive and negative affect: the PANAS scales. Journal of Personality and Social Psychology, 54, 1063-1070.

Weinberg, R. S. (1988). The mental advantage: Developing your psychological skills in tennis. Champaign, IL: Leisure Press.

Weinberg, R. S., \& Williams, J. M. (2001). Integrating and implementing a psychological skills training program. In J. M. Williams (Ed.), Applied sport psychology: Personal growth to peak performance (pp. 347-377). Mountain View, CA: Mayfield. 
Williams, J. M. \& Krane, V. (2001). Psychological characteristics of peak performance. In J. M. Williams (Ed.), Applied sport psychology: Personal growth to peak performance (pp. 162-178). Mountain View, CA: Mayfield.

Yerkes, R. M., \& Dodson, J. D. (1908). The relation of strength of stimulus to rapidity of habit formation. Journal of Comparative Neurology of Psychology, 18, 459-482. 
Table 1

Mean Positive (PA) and Negative Affect (NA) Scores Across Music Conditions (N = 14)

\begin{tabular}{|c|c|c|c|c|c|c|c|c|}
\hline \multirow[b]{2}{*}{ Music Condition } & \multicolumn{2}{|c|}{ Pre-task PA } & \multicolumn{2}{|c|}{ Post-task PA } & \multicolumn{2}{|c|}{ Pre-task NA } & \multicolumn{2}{|c|}{ Post-task NA } \\
\hline & M & $\mathrm{SD}$ & M & $\mathrm{SD}$ & M & SD & M & $\mathrm{SD}$ \\
\hline No Music & 22.29 & 7.52 & 19.36 & 6.44 & 20.79 & 3.70 & 19.64 & 5.37 \\
\hline Preparation Music & 24.36 & 5.77 & 19.07 & 6.34 & 19.57 & 4.27 & 20.07 & 8.95 \\
\hline During Music & 22.50 & 7.80 & 18.86 & 7.19 & 20.14 & 4.47 & 19.00 & 7.19 \\
\hline
\end{tabular}

Note: Possible total PA and NA scores range from $10-50$. 


\section{APPENDIX A}

Pilot Research Questionnaire 


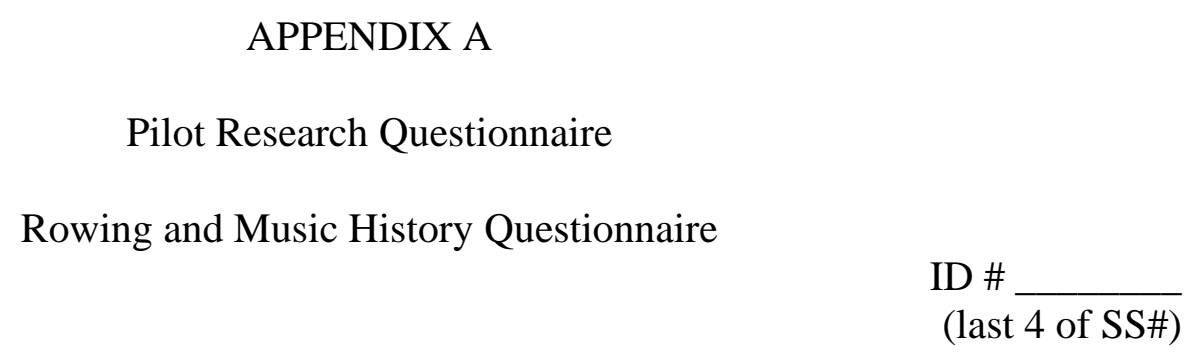

1. Approximately how long have you been involved in rowing? Please include all levels of competition for which you have participated.

years months

Please answer the following questions as they pertain to your normal PREPARATION and WARM-UP prior to an erg test.

2. How long do you spend in preparation and warm-up prior to participating in an erg test? Minutes

3. How often do you use music as part of your preparation before an erg test?

1

2

3

Never
4 5 6 Always

4. If you use music as part of your preparation, why do you use it? Please check all that apply.

Energizing; to raise my intensity

Relaxation; to lower my intensity

$\square$ Focus and Concentration

To block out distractions

$\square$ Other:

5. If you do NOT use music as part of your preparation, why don't you use it? Please check all that apply.

$\square$ It energizes me too much

$\square$ It relaxes me too much

It's distracting

$\square$ I've never thought to use music before

$\square$ I use an alternative preparation strategy:

Please turn this page over and complete the questions on the other side. 
Please answer the following questions as they pertain to you DURING an erg test.

6. During an erg test, how much do you notice or attend to the other people who are erging beside or around you?
1
2
3
4
5
6
None
A lot

7. How often do you use music during an erg test?
2
3

1

4

5

6

Never

Always

8. If you do listen to music during an erg test, do you prefer to use:

$\square$ Headphones

$\square$ A Boombox / Stereo

9. How comfortable would you be if you were asked to use headphones to listen to music during an erg test?
12
3
4
5
6
Very

Very

Uncomfortable

Comfortable

10. If you use music in any way for rowing, please check all of the following that apply to when you specifically use music for rowing:

$\square$ Before practice

$\square$ Before erg tests

$\square$ Before competition

$\square$ During practice

During erg tests

$\square$ Other:

11. If you use music in any way for rowing, how long have you been using it? years months

Thank you for taking the time to answer these questions. Your input is greatly appreciated! 


\section{APPENDIX B}

Positive and Negative Affect Schedule (PANAS) 


\section{APPENDIX B}

Positive and Negative Affect Schedule (PANAS)

ID \# (last 4 of SS\#)

This scale consists of a number of words that describe different feelings and emotions. Read each item and then mark the appropriate answer in the space next to the word. Indicate to what extent you feel this way right now, that is, at the present moment.

1

very slightly or not at all
3

moderately
4

quite a bit
5

extremely

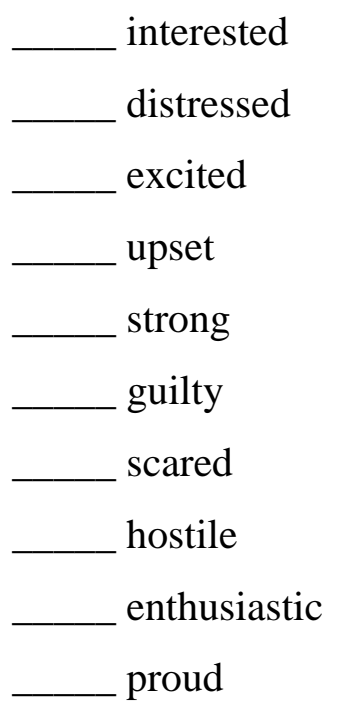

\begin{tabular}{ll} 
& irritable \\
alert & ashamed \\
& inspired \\
& nervous \\
& determined \\
\hline & attentive \\
& jittery \\
& active \\
& afraid
\end{tabular}




\section{APPENDIX C}

Informed Consent 


\title{
APPENDIX C
}

Informed Consent

\section{CONSENT and INFORMATION FORM}

\author{
Effects of Listening to Music in a Precompetition Routine on Mood and Performance
}

Introduction. I have been asked to participate in this research study which has been explained to me by John R. Geer, a member of the Sport Psychology Program at West Virginia University. This research is being conducted to fulfill the requirements for a master's thesis in physical education in the School of Physical Education at West Virginia University.

Purpose of the Study. The purpose of this study is to better understand the effects of listening to music as part of a precompetitive routine on mood states and performance. As a participant, I will be asked to complete a music history questionnaire and I may be asked to compile a 20minute music tape/CD with personally selected song choices. I may be asked to complete three rowing erg tasks, each during separate sessions held during normal practice time. I may be asked to complete a basic demographic questionnaire, as well as a questionnaire designed to assess mood.

Description of Procedure. Participation in the study will take place during, and will not exceed, normally scheduled practice time. There will be approximately 45 total participants in this study. All participants will be asked to attend a brief introductory session where they will be asked to complete a music history questionnaire. During the second phase of the study, approximately 20 of the participants will be asked to complete a demographic questionnaire and will be given instructions regarding their need to compile a 20 minute music tape/CD with personally chosen song choices for use during the study. These 20 participants will be asked to perform three 2000-meter rowing erg tasks on different dates in which they will use headphones to listen to music either not at all, before, or during the tasks. Prior to and immediately following the erg tasks, participants will be asked to complete a mood questionnaire. I understand that I do not have to answer all the questions if I do decide to participate. The questionnaires will take approximately one minute each to complete and I can ask to see the questionnaires before signing this consent form.

Risk and Discomforts. There is the possibility of injury occurring from my participation in the erg tasks, but the risks of injury are not greater than during participation of normal varsity rowing practice. The 2000-meter erg tasks will be no different than those that would normally be completed during regular practice. Furthermore, some mild discomfort may follow participation due to muscle aches. I have agreed to participate, and I believe myself to be in good health.

Alternatives. I understand that I may choose not to participate in this study.

July 16, 2003

Page 1 of 2

Initial

Date 


\section{Effects of Listening to Music in a Precompetition Routine on Mood and Performance}

Benefits. I understand that this study is not expected to be of direct benefit to me, but the knowledge gained may benefit me by helping me to determine the effects of listening to music during a precompetition routine on mood and performance.

Contact Persons. For more information about this research, I can contact John R. Geer at (xxx) xxx-Xxxx or name@email.com. For information regarding my rights as a research subject, I may contact the Executive Secretary of the Institutional Review Board for West Virginia University at (304) 293-7073.

Confidentiality. I understand that any information about me obtained as a result of my participation in this research will be kept as confidential as legally possible. In any publications that result from this research, neither my name nor any information from which I might be identified will be published without my consent.

Voluntary Participation. Participation in this study is voluntary. I understand that I am free to withdraw my consent to participate in this study at any time. Refusal to participate or withdrawal from this study will involve no penalty. I understand that my standing on the WVU rowing team will not be affected by refusal to participate or withdrawal from the study. I have been given the opportunity to ask questions about the research, and I have received answers concerning areas I did not understand. I understand that I will receive a copy of this consent form.

Date:

Participant (sign)

Investigator (sign)

Print name

Print name

July 16, 2003

Page 2 of 2

Initial

Date 


\section{APPENDIX D}

\section{Demographic Questionnaire}




\section{APPENDIX D}

Demographic Questionnaire

$$
\text { ID \# }
$$

1. Approximately how long have you been involved in rowing? Please include all levels of competition for which you have participated.

years months

2. How often do you use music as part of your preparation before an erg test?

1

Never
2

3

4

5

6

Always

3. How often do you use music during an erg test?

12

Never
4

5
6

Always

4. If you do listen to music during an erg test, do you prefer to use:

$\square$ Headphones

$\square$ A Boombox / Stereo

5. If you use music in any way for rowing, please check all of the following that apply to when you specifically use music for rowing:

$\square$ Before practice

$\square$ Before erg tests

$\square$ Before competition

$\square$ During practice

$\square$ During erg tests

$\square$ Other:

6. If you use music in any way for rowing, how long have you been using it? years months 
Table 2

Mean Performance Times (sec) Across Music Conditions ( $\mathrm{N}=14)$

\begin{tabular}{lcc}
\hline & M & SD \\
\hline No Music Group & 492.99 & 26.66 \\
Preparation Music Group & 490.77 & 26.37 \\
During Music Group & 492.98 & 26.42 \\
\hline
\end{tabular}


Table 3

Intercorrelations Between Pre- and Post-task Positive (PA) and Negative Affect (NA) and Performance Time in the No Music Group ( $\mathrm{N}=14)$

\begin{tabular}{lccccc}
\hline & 1 & 2 & 3 & 4 & 5 \\
\hline 1. Pre-task PA & -- & .40 & .04 & .03 & -.17 \\
2. Post-task PA & & -- & -.33 & -.42 & -.11 \\
3. Pre-task NA & & & -- & $.58^{*}$ & .04 \\
4. Post-task NA & & & & -- & -.23 \\
5. Performance Time & & & & & -- \\
\hline
\end{tabular}

${ }^{*} p<.05$, two-tailed. 
Table 4

Intercorrelations Between Pre- and Post-task Positive (PA) and Negative Affect (NA) and Performance Time in the Preparation Music Group $(\mathrm{N}=14)$

\begin{tabular}{lccccc}
\hline & 1 & 2 & 3 & 4 & 5 \\
\hline 1. Pre-task PA & -- & .49 & -.30 & .30 & $-.64^{*}$ \\
2. Post-task PA & & -- & .14 & .36 & -.35 \\
3. Pre-task NA & & -- & .24 & .03 \\
4. Post-task NA & & & -- & .09 \\
5. Performance Time & & & & -- \\
\hline
\end{tabular}

$* p<.05$, two-tailed. 
Table 5

Intercorrelations Between Pre- and Post-task Positive (PA) and Negative Affect (NA) and Performance Time in the During Music Group (N = 14)

\begin{tabular}{lccccc}
\hline & 1 & 2 & 3 & 4 & 5 \\
\hline 1. Pre-task PA & -- & $.69 * *$ & $.57^{*}$ & .11 & -.19 \\
2. Post-task PA & & -- & .24 & -.18 & -.03 \\
3. Pre-task NA & & -- & .24 & .15 \\
4. Post-task NA & & & -- & .21 \\
5. Performance Time & & & & -- \\
\hline
\end{tabular}

${ }^{*} p<.05$, two-tailed. ${ }^{* *} p<.01$, two-tailed. 


\section{SELECTED REVIEW OF LITERATURE}

The competitive nature of sport and athletics drives athletes and coaches to find ways of enhancing performance. As a result, there is an ever-increasing list of specific strategies (e.g., nutrition, strength training, etc.) that can be utilized before and during competitions to try and achieve enhanced performance. However, it is now recognized that many other factors outside of these specific strategies, such as concentration and anxiety regulation, can have important effects on how athletes perform. Therefore, as a further attempt to improve performance, coaches, athletes, and sport psychology consultants have also placed an emphasis on improving various mental preparation strategies that lead up to competition. This has given rise to the notion of using precompetition routines as a way to standardize athletic preparation and, hopefully, increase the consistency of athletic performance. Because these routines may include a multitude of preparation strategies (e.g., imagery, relaxation, self-talk, listening to music), there is a need to understand whether they actually aid in the preparation of athletic performance. This chapter is a selected review of the literature pertaining to: (a) precompetition routines and, (b) music in sport and exercise, and concludes with a summary of the reported literature.

\section{Precompetition Routines}

One preparation strategy that has been suggested to increase the consistency of performance is the use of precompetition routines. Precompetition routines are systematic preparation plans comprised of both physical and mental components that serve a variety of purposes in preparing an athlete for competition (Davies, 1989; Gould, Eklund, \& Jackson, 1992; Orlick, 1986; Orlick \& Partington, 1988; Taylor, 1995; Taylor \& Wilson, 2002; Weinberg, 1988; Weinberg \& Williams, 2001). From a physical standpoint, these routines can include standardized warm-ups (Davies, 1989), equipment use (Taylor \& Wilson, 2002), sleeping 
patterns (Nideffer, 1985), stretching, and eating habits (Weinberg, 1988). Mentally, routines can be comprised of positive self-talk (Orlick, 1986), imagery (Taylor \& Wilson, 2002), relaxation (Nideffer, 1985), concentration (Weinberg, 1988), and listening to music for psych-up (Thiese \& Huddleston, 1999).

A common misperception about precompetition routines that is addressed within the literature is that they include ritualistic behavior. It is important for athletes, coaches, and performance enhancement consultants to be able to distinguish between routines and rituals. While at times these two behaviors may seem very similar, they serve very different functions for the athlete. Both routines and rituals are behaviors that an athlete may perform either prior to or during performance. But unlike routines, rituals can be classified as rigid, superstitious behaviors that do not have a realistic, purposeful role in preparation (Taylor \& Wilson, 2002). They can be easily observed among athletes in a variety of sports. Some examples include, the volleyball player who never steps on a line getting onto the court, the soccer player who wears the same "lucky" undershirt for every game, and the baseball player who must readjust his batting gloves five times before each pitch. Athletes who perform rituals truly believe that their performance is heavily contingent upon performing their rituals (Taylor \& Wilson, 2002). This improper attribution of cause and effect can lead to unwanted anxiety and decreased confidence if the rituals are broken (Weinberg, 1988). On the other hand, routines involve purposeful behaviors that have a functional role in preparing athletes for competition. Examples of purposeful routines include physical warm-ups, stretching, and the use of imagery before competition. These routine components have the flexibility to be adapted to changing circumstances or environments and require systematic training to be effective (Taylor \& Wilson, 2002). 


\section{Qualitative Support for Routines}

To assess the validity and usefulness of precompetition routines, it is useful to examine the qualitative research centered on elite (i.e., Olympic) athletes with the purpose of understanding the facilitative and debilitative factors affecting peak performance (Eklund, Gould, \& Jackson, 1993; Gould et al., 1992; Gould, Guinan, Greenleaf, Medbery, \& Peterson, 1999; Greenleaf, Gould, \& Dieffenbach, 2001; Orlick \& Partington, 1988). These studies conducted interviews with athletes who competed in both summer and winter Olympic games regarding the factors they perceived to have an effect on their performance. Through interviews with 20 members of the 1988 United States Olympic Wrestling Team about their all-time best matches, Gould, Eklund, and Jackson (1992) found that 55 percent $(n=11)$ used match preparation routines, including both physical (e.g., warm-up) and mental (e.g., imagery) components. When asked about their worst match, 10 of the 20 wrestlers cited nonadherence to their match preparation routine as being a negative influence on their performance. In a followup study with the same Olympic wrestling team, Eklund, Gould, and Jackson (1993) examined the six members who won medals at the 1988 Olympic games. They found that the medalists were typified by systematic preperformance routines that were consistently adhered to throughout their matches.

Other research interviewed selected athletes from 8 United States teams who competed at the 1996 Summer Olympic Games (Gould, et al. 1999). Their results found that the teams who had met performance expectations for the games cited adherence to mental preparation plans as a positive contributor to their success. On the other hand, teams who failed to meet performance expectations listed a lack of preparation plans or lack of adherence to preparation plans as a negative factor influencing their performance. Overall, in this line of literature, discussions with 
those athletes that won medals, met expectations, or had their best matches revealed that using systematic precompetition routines was self-reported as a contributing factor to their success (Eklund et al., 1993; Gould et al., 1992; Gould et al., 1999; Orlick \& Partington, 1988). Conversely, non-adherence to or straying from established routines was cited as one of the major factors that debilitated performance in non-medalists and in those who failed to meet expectations (Gould et al., 1993; Gould et al., 1999).

In general, the elite athletes who used precompetition routines reported the use of a variety of components within their routines. Some of the mental strategies utilized included visualization, imagery, positive self-talk, and focusing on strengths. Among the physical tactics used in their routines, the athletes reported using systematic warm-ups and controlled breathing exercises (Eklund et al., 1993; Gould et al., 1992). While some overlap occurred in the components comprising these athletes’ precompetition routines, Eklund et al. (1993) emphasizes that each routine was individually tailored to the athlete's specific needs and utilized diverse components.

While this line of qualitative research appears to support the notion of using precompetitive routines, it is important to keep in mind that the results were obtained through retrospective self-report. Therefore, it is difficult to assess the actual magnitude of the effect routines had on the athletes. The conclusions drawn from the results are based on the perceptions of the athletes and not on empirical data.

\section{Purposes for Using Precompetition Routines}

Unfortunately, within the literature, there is little actual research which supports why precompetition routines are useful to athletes. Therefore, authors have relied on theorizing and speculating about the purposes routines serve. One of these speculated useful purposes for 
precompetition routines is that they help to give athletes a sense of control over their physical environment. Typically, the general physical components of the competitive environment for each sport are fairly standard. Therefore, athletes have the opportunity to become familiar with their physical surroundings, what takes place in this setting, and how to physically interact with the environment (Weinberg \& Williams, 2001). This can be easily accomplished for home competition sites, but may be more difficult for away facilities. It is suggested that, if possible, coaches should attempt to expose their athletes to their opponents' competition sites prior to actual competition either through physical exposure or at the least through the use of videos and photographs. Either of these methods will increase the level of familiarity to the external environment (Weinberg \& Williams, 2001). By becoming more aware of their physical surroundings, athletes can more easily focus and control their inner environment (i.e., their thoughts and cognitions, their emotions, and their mental images) and how it aids in their mental preparation (Weinberg \& Williams, 2001).

By gaining this sense of control, it is theorized that athletes limit feelings of nervousness or uncertainty that may arise from being placed in an unfamiliar environment. Therefore, another purpose of precompetition routines is to help athletes increase their confidence and reduce their anxiety leading up to competition (McCann, 1995; Orlick, 1986; Taylor \& Wilson, 2002). The routines set up specific instructions for the athletes regarding how to optimally prepare for competition. Implementing and completing each of the preparatory steps of a routine gives athletes reassurance and confidence that they have done all they can to prepare for the competition (McCann, 1995). It is commonly theorized that athletes become more anxious prior to competitions they perceive to be of greater importance. Using a standardized precompetitive routine to prepare for competitions, regardless of importance, helps athletes address each 
competition with similar expectations for performance and success, thereby reducing their anxiety (Taylor \& Wilson, 2002).

In addition to decreasing the level of anxiety felt by athletes prior to competition, precompetitive routines can also help athletes limit the possibility of other distractions interfering with their preparation (McCann, 1995). Routines establish where and how an athlete's time will be spent leading up to the time of competition. Consistently carrying out these routines will theoretically decrease the likelihood that an athlete will become involved in other potentially distracting activities and thoughts. As a result, the routines can enable athletes to gradually and progressively narrow their concentration and focus on their upcoming competition (Davies, 1989; Weinberg, 1988).

It should be noted that the preceding purposes of using precompetitive routines are based upon theoretical hypotheses drawn from the research on preperformance routines for self-paced tasks (e.g., basketball free-throws, golf putting, tennis serves). These specific types of routines have been proven to increase the consistency and quality of performance on various self-paced tasks (Boutcher \& Crews, 1987). Cohn (1990) proposes that the most useful theory for explaining the effectiveness of these preperformance routines is schema theory which, "holds that each motor movement is stored in memory in the form of a generalized motor pattern that may be retrieved and executed” (p.302). Once the schema for the skill has been practiced and memorized, the athlete can then recall the schema, when needed, to execute the skill in the same manner each time, thereby increasing the consistency and effectiveness of their performance. While research supports the schema theory for preperformance routines with self-paced tasks (Boutcher \& Crews, 1987), further research has yet to test this theory with generalized precompetition routines on overall performance consistency and quality. 


\section{Developing Precompetition Routines}

In general, many authors agree that the development of a precompetition routine should not have to take place from scratch (McCann, 1995; Miner, Shelley, \& Henschen, 1995; Taylor \& Wilson, 2002). Often athletes already have a loose routine or set of behaviors that they use to help prepare them for a competition. However, the athletes may or may not be aware that they are performing these behaviors, resulting in a lack of consistent preparation (Weinberg \& Williams, 2001). In order to help increase an athlete's level of awareness of their preparatory behaviors, several authors suggest it is often very useful to have them identify and reflect upon how they prepared for past performances (Miner, et al., 1995; Orlick, 1986; Taylor \& Wilson, 2002; Weinberg \& Williams, 2001). Specifically, it is important for athletes to examine their preparations before competitions in which they performed well and before those in which they performed poorly. To assist athletes, one author suggests using an assessment such as the Competition Reflections form to aid athletes in recognizing important differences in performance preparations (Orlick, 1986). This form helps athletes analyze not only their physical preparations, but also their feelings, self-talk, level of anxiety and concentration leading up to competition.

The examination of preparation should not be limited to the period of time just before performance. Rather, athletes should also attempt to reflect on their preparation the day before competition, the night before competition, and the entire day of competition. Miner et al. (1995) contends that for each of these periods of time, athletes should think about the specific activities they engaged in and then attempt to classify each as being facilitative or debilitative to their performance. In addition, they suggest it is helpful for athletes to think back to how they handled the various mental aspects of preparation, such as level of anxiety or activation, 
attentional focus, emotionality, and self-talk (Miner et al., 1995). By assessing their history of preparation prior to good and poor performances, it is theorized that athletes will be able to identify the behaviors previously used to aid their performance and then incorporate them into the development of a new, standardized precompetition routine (Orlick, 1986).

The information that results from reflecting on past performances emphasizes the fact that no two athletes are alike. Numerous strategies may be employed to facilitate appropriate preparation in different athletes. Therefore, it is very important for coaches and performance enhancement consultants to kept in mind that precompetitive routines must be individualized to each athlete, even among those who may be on the same team, rather than use one general strategy across individuals (Taylor, 1995). Before implementing preparation strategies into a routine, it is important to assess and understand the unique psychological needs of each athlete. Taylor (1995) suggested using a variety of tools, such as subjective assessments (e.g., interviews with the athlete and teammates), objective assessments (e.g., Competitive State Anxiety Inventory -2), and observations as a means of gaining insight into these needs. He suggests that some of the more important psychological characteristics to assess in each athlete that have been cited in the literature include their motivation, confidence, intensity, and concentration (Taylor, 1995).

In addition to each athlete having unique preparation needs, different sports require different psychological preparation as well (Taylor, 1995). Knowledge of the specific physical and mental demands of a sport provides information to athletes as to how to focus the various aspects of their preparation. In particular, it is important to assess the physical, technical, and logistical requirements for each sport (Taylor, 1995). Similarly, different sports may require varying levels of intensity for optimal performance (Billing, 1980). For example, compare the 
physical preparation necessary for two members of the same track team competing in different events (i.e., a 100-meter sprinter and a 5000-meter distance runner). The physical demands of each event are very different and, subsequently, may require differing preparation strategies. For example, the sprinter may try to increase his/her intensity prior to competing due to the explosive nature of sprints, and the distance runner may prefer a more moderate intensity level leading into a race that can be sustained throughout. While this is an extreme example, it illustrates the point that knowledge of specific sport demands is necessary in order to appropriately tailor an athlete’s focus in a precompetition routine.

Again, it should be mentioned that the specific development of precompetition routines has been addressed in sport psychology textbooks, but not in the empirical literature. The suggestions offered by the preceding authors on how to develop a precompetition routine are based on theory, research performed with preperformance routines for self-paced tasks, and their experience working with athletes.

\section{Implementing Precompetition Routines}

Once the general components and focus of a precompetition routine have been identified for a particular athlete, the next step involves combining them into a systematic plan that will optimize the opportunity for that athlete to be in an ideal performance state prior to competition (Taylor \& Wilson, 2002). Typically, routines begin the day before competition and usually involve both physical and mental preparation (McCann, 1995; Miner et al., 1995). Training and workouts on the day prior to competition can be inconsistent and a potential source of disruption to an athlete's preparation. Many coaches tend to taper their training regiments the day or week before a competition to ensure that their athletes are well rested with plenty of energy (Nideffer, 1985). However, in some sports, this lightened training load represents a deviation from an 
athlete's normal physical activation and can cause the build up of extra energy. While the availability of extra energy might seem desirable, it can have negative consequences in the form of the inability to fall asleep. Therefore, the athlete awakes on the morning of competition with less rest and rejuvenation than normal (Nideffer, 1985).

Appropriate mental skills can be used to help compensate for such a change in physical preparation. Relaxation training is a popular method utilized by athletes to cope with sleep disturbance problems. Proper use of relaxation skills can channel an athlete's energy or attention and facilitate rest and sleep (Nideffer, 1985). The important concept for athletes and their coaches to remember is that their physical and mental preparation on the day prior to competition should always be consistent. If coaches wish to taper their training, they should ensure that they do so before every competition so that the athletes know what to expect and can plan the use of other mental skills appropriately (Weinberg \& Williams, 2001).

The next phase of a precompetitive routine occurs on the morning of the competition. By beginning the routine early in the day, it is proposed that athletes can establish a positive and productive atmosphere that will guide the remainder of the preparation leading up to the time of competition. It is even suggested that athletes begin mental preparation before they get out of bed (Taylor \& Wilson, 2002). Athletes can use imagery to run through their performances as a means of facilitating positive self-talk and focus. Physical preparation also begins early in the day in the form of pre-game meals. Depending on the time of the competition, this can be an important part of a precompetitive routine. Often competitions do not take place at the same time of day. Therefore, when athletes eat and what they eat prior to competition can be very important. Once again, this aspect of the routine is individualized among athletes, with each athlete establishing a personal preference. Weinberg (1988) offered a few useful guidelines 
promoted by nutritionists and exercise physiologists, such as avoiding spicy and fatty foods, consuming foods with high levels of carbohydrates, and drinking plenty of liquids such as water and juices.

As athletes arrive at the location of the competition, their physical and mental preparation continues, although at a higher level of concentration and intensity (Taylor \& Wilson, 2002; Weinberg, 1988). Athletes who use routines generally perform a standardized warm-up, including physical (e.g., jogging) and technical (e.g., practicing a golf swing) warm-up and stretching. Although stretching most notably aids in the prevention of injury and the increase in range of motion, it can also facilitate relaxation and a decrease in anxiety (Weinberg, 1988). This mental state is ideal for using imagery to focus on the upcoming competition. It is recommended that athletes warm-up using fun and enjoyable drills that can be performed well. This will serve to increase confidence and initiate positive self-images and self-talk in the athletes (Davies, 1989).

The final phase of precompetitive routines occurs immediately prior to the competition. At this point the routine assists in the "fine-tuning" of athletes "mentally and physically to their optimal state of readiness” (Taylor \& Wilson, 2002, p. 125). The first component of the routine at this phase is that all sport specific equipment should be properly checked and attuned to ensure it is ready to go (Fink \& Taylor, 2002). This can limit the possibility of any last minute anxiety caused by equipment failure at the start of the competition. For example, a basketball player tightening up the laces on his or her shoes early will allow time to deal with a broken shoelace before the competition begins. Next, athletes should engage in final mental and physical preparation. Mentally, this includes more performance imagery, the use of attentional or focus cues, and positive self-talk. Physical preparation concludes with any final warm-ups or technical 
adjustments (Taylor \& Wilson, 2002). The correct, systematic implementation of each of these precompetitive routine phases will help to gradually narrow an athlete's attention and focus, prepare their body physically to perform, and increase the consistency of reaching an ideal performance state (Davies, 1989; Miner et al., 1995; Orlick, 1986; Weinberg, 1988). It should be noted that the guidelines put forth by the preceding authors regarding the implementation of precompetition routines are based mostly upon theory and personal experiences. Little, if any research has been published examining the effectiveness of these guidelines.

\section{Routine Flexibility}

Because precompetition routines are specific to each athlete, it is difficult to create a highly effective routine on the first try. As mentioned, one of the important distinctions between routines and rituals is that routines are flexible and open to change (Taylor \& Wilson, 2002). Therefore, after developing a preliminary routine, the athlete should use the preseason and offseason to experiment through a process of trial and error to find out which components in the routine are effective and which are not (Miner et al., 1995; Weinberg \& Williams, 2001). Throughout training, athletes, along with coaches and performance enhancement consultants, should constantly seek to assess and refine their routines in an attempt to increase the level of performance preparation (Orlick, 1986). In other words, precompetition routines are never perfect, but rather are constantly evolving and being improved.

Unfortunately, in the world of sport there are many factors that are simply out of the athlete's control (e.g., weather, officiating, opponents' facilities). Therefore, it is important that athletes not develop a dependence on their routines to prepare them to perform. Building flexibility into precompetition routines can help athletes cope with unexpected factors that may interfere with the routine or performance (Davies, 1989; Orlick, 1986; Weinberg, 1988). 
Weinberg (1988) recommended that coaches and athletes simulate competition during training sessions to give athletes an opportunity to practice their routines. But, he also recommends athletes perform in a simulation of competition without using their routine. As a result, the athletes gain confidence and understanding that they can still perform well even when they are unable to implement their full precompetition routines. Another way routines can be modified to adjust to changes is to have athletes develop two variations of the same routine. For example, an athlete could have a routine to follow when everything is normal and they are feeling good and another routine to use when things are not going well or preparation time is limited (Orlick, 1986). Consequently, the athlete would be still be able to systematically prepare for competition even though preparation did not begin under good conditions. Overall, incorporating flexible coping strategies to deal with unexpected factors is a highly recommended component of an athlete’s precompetitive routine (Fink \& Taylor, 2002).

Despite the lack of empirical research, many authors have provided a strong theoretical basis for the purpose, development, and implementation of precompetition routines. However, athletes, coaches, and sport psychology consultants should recognize the importance of individualizing these routines by selecting specific routine components that will be most effective for each particular athlete. As precompetitive routines begin to gain in popularity, new research is needed to help understand the usefulness of these specific components, as well as help identify new strategies that may be incorporated into routines (e.g., listening to music for “psyching up” or relaxation).

\section{Music in Sport and Exercise}

It is often subjectively reported that music can have a powerful effect on human thought and behavior (Gluch, 1993; Hohler, 1989; Karageorghis \& Terry, 1997; Losel, 2000; Lucaccini 
\& Kreit, 1972). As humans perceive music, its various components (i.e., melody, rhythm, tempo, etc.) are processed by the central nervous system into information that can elicit mental and physical responses (Losel, 2000). There has been an increasing trend in the literature that has studied and has speculated on the effects music has in sport and exercise (Karageorghis \& Terry, 1997; Lucaccini \& Kreit, 1972). Due in part to this trend, music has begun to receive attention as a potentially effective component to athletic preparation and precompetitive routines (Gluch, 1993; Stevens \& Lane, 2001; Thiese \& Huddleston, 1999).

Effects of Music in Sport

One of the first reviews looking at the music and sport literature was conducted by Lucaccini and Kreit (1972). This review highlighted the important findings of that time regarding the impacts of music as an ergogenic aid. One impact studied was how music has an effect on mood and physiology. While it may be easier to identify the physical effects music can have on the human body, it is much more difficult to pinpoint and measure the psychological and emotional impacts. However, it appears that some songs and sounds do create specific emotional and affective responses in humans. Lucaccini and Kreit contend that one theory places emphasis in the components of music affecting mood according to a specific, uniform manner. Hevner's system of studying the effects of music on mood (as cited in Lucaccini \& Kreit, 1972) assigned values to the elements of music (i.e., mode, tempo, pitch, rhythm, harmony, and melody). These values could then be used to create defined patterns (e.g., graceful-sparkling) for music that related to corresponding emotional responses.

However, Hevner’s system was criticized for failing to take into account individual differences among listeners. Strong arguments assert that a person’s culture, personality, personal experiences, and situational factors all help to characterize how a person responds 
emotionally to music (Losel, 2000; Lucaccini \& Kreit, 1972). The basis of this rebuttal can be understood by applying learning theory towards listening to music. A person’s emotional response to a particular musical selection may be affected by one's mood associated with previous experience with that musical selection (Lucaccini \& Kreit, 1972). If a song is heard repeatedly during an emotionally significant situation, a person will tend to associate a larger emotional response to that song in the future (Losel, 2000). For example, an athlete may hear a song following a victory in an important contest, and the positive mood associated with winning may become tied to that song. When the athlete hears that song in the future, he or she may be able to draw on their previous experience and elicit positive feelings.

However, Lucaccini and Kreit concluded that the association between music and physiological responses (e.g., heart rate, respiration rate) appears to be weak and inconsistent. Again, individual differences (e.g., musical training, personal significance, type of music played) are said to contribute to the inconclusive results. Furthermore, the small changes in physiological responses resulting from listening to music did not seem to be related to changes in mood (Lucaccini \& Kreit, 1972).

In determining the effects of music on physiology, much of the research has used heart rate as a dependent measure. One study by Copeland and Franks (1991) examined differences in participants' $(n=24)$ heart rate across three music conditions during a treadmill exercise in which participants ran to voluntary exhaustion. Their results yielded that a slow/soft music condition resulted in a lowered heart rate when compared to the fast/upbeat and no (control) music conditions. However, other studies have failed to produce evidence of a musical influence on heart rate. For example, an experiment by Johnson and Siegel (1987) looked at the effects on participants’ $(n=26)$ heart rates across three attention manipulation conditions (arithmetic 
problems, loud music, and control) during a running treadmill exercise. They failed to find significant differences in heart rate between the music and non-music conditions. Overall, the body of research examining the effects of music on heart rate appears inconsistent, supporting the review by Lucaccini and Kreit (1972). A contributing factor to these equivocal results may be the variety of research designs utilized throughout the literature (Karageorghis \& Terry, 1997). Standardized procedures and replication of research designs need to be employed before more definitive statements may be made regarding the effects of music on physiology.

In a more recent review of the literature examining the effects of music in sport and exercise, Karageorghis and Terry (1997) have suggested a conceptual framework from which to view the psychophysical effects of music. Their first hypothesis stated that music serves to narrow the attention of the listener, thereby reducing negative sensations such as fatigue and pain. As support for this hypothesis, several authors have drawn upon information processing theories, noting that there is a limited amount of information that a person can process at any one time (Karageorghis \& Terry, 1997). Therefore, when a person's attention is divided between the demands of the task and the listening of music, there is less available attention to devote to physical and psychological feedback (i.e., fatigue), thus improving mood states. By this account, music might be considered an appropriate component of precompetitive routines. Since one of the theorized purposes of using routines is to help athletes narrow their attention in order to focus on their competition, listening to music may help facilitate this focusing.

A study performed by Rejeski (1985) examined rates of perceived exertion during high intensity exercise. He explained how during exercise, sensory and emotional information is processed in parallel (i.e., subconsciously). He concluded that at high levels of intensity, a person's attention is more focused on these internal sensations of fatigue. But, as the intensity of 
the exercise decreases, other cues, such as music, may dominate attentional focus (Rejeski, 1985). Additional findings by Johnson and Seigel (1987) support Rejeski’s theory, in that listening to music was found to decrease the level of perceived fatigue (i.e., rate of perceived exertion) significantly more than when performing another attentional manipulation.

Karageorghis and Terry’s (1997) second conceptual hypothesis proposed that music could alter levels of arousal by either psyching up or calming down athletes before performance. But while this notion has been advocated by several authors in the field of sport psychology (Brown, 1980; Hohler, 1989; Taylor \& Wilson, 2002), there appears to be little research supporting the hypothesis (Karageorghis \& Terry, 1997). Gfeller (1988) theorized that the arousing effects of music are related to whether or not an athlete can evoke a deep, associative response to the music. When such a connection is made to the music, the person can develop motivating thoughts of physical activity or relaxation. However, this response is not only attributable to the musical selection, but also to the individual differences of the athlete (e.g., culture, experiences) (Lucaccini \& Kreit, 1972). In addition, it is suspected that music may affect arousal through a process of controlling anxiety. Unfortunately, research in this area has provided mixed results, with some studies supporting and others rejecting the musical effects (activation and relaxation) on anxiety (Karageorghis \& Terry, 1997).

The third conceptual hypothesis put forth by Karageorghis and Terry (1997) contended that people have an inherent tendency to synchronize movement with the rhythm of music. This is particularly applicable to athletic tasks that feature repetitious movements (e.g., running, cycling, rowing). Studies examining this effect have noted that listening to synchronous music (i.e., music that is synchronized with movement) during motor skills tasks improved output and endurance, whereas listening to asynchronous music did not (Karageorghis \& Terry, 1997). 
Authors have theorized that listening to music can affect or change mood states, and that these modified mood states may then have an effect on athletic performance (Hohler, 1989; Lucaccini \& Kreit, 1972). Again, it is useful to drawn upon Rejeski’s (1985) parallel processing hypothesis. He asserted that at low exercise levels, external stimuli such as music are more easily processed and may reduce rates of perceived exertion. However, during higher intensity exercise, physiological stimuli such as pain and fatigue are more likely to dominate a person’s thoughts and increase rates of perceived exertion. Testing this hypothesis, a study by Boutcher and Trenske (1990) examined mood states of participants $(n=24)$ across three different stimulus conditions (control, sound deprivation, and music) during an 18-minute cycle ergometry task performed at varying intensities. It was found that participants listening to music at moderate and heavy intensities possessed more positive mood states and lower rates of perceived exertion (Boutcher \& Trenske, 1990). Despite the hypothesis of Rejeski (1985), it appears that music can have an effect on mood and rates of perceived exertion at high intensity levels. Further research by Lee (as cited in Karageorghis \& Terry, 1997) found that listening to fast, upbeat music elicited significantly higher positive and significantly lower negative mood states than when listening to either slow or no music conditions. These studies provide fairly strong evidence that music can be used to influence affective mood states during exercise.

However, it is important to point out that individual differences, such as personality traits, may account for differences in changes in mood. Previous research by Prapavessis and Grove (1994) examined personality variables as predictors of precompetitive mood states in 121 competitive shooting athletes. Participants were given a battery of personality inventories and the researchers' abbreviated version of the Profile of Mood States (POMS). Results showed that three personality variables (Trait-sport Confidence, Goal-orientation, and Attributional-style) 
were significant predictors of precompetitive mood states. Further support for the relationship between personality variables and precompetitive mood was found by Hassmen, Koivula, and Hansson (1998). In their study, male golf participants $(n=8)$ completed four personality trait inventories and the POMS prior to several performances and found that differences for the trait measures of Neuroticism, Locus of Control, and Trait Anxiety corresponded to differences in precompetition mood scores. Specifically, participants who scored higher on these three trait measures scored significantly higher on the Anger, Tension, and Depression subscales of the POMS. Therefore, changes in mood as a result of listening to music may vary based on differences in personality traits of the participants.

Music in Preparation for Performance

Historically, much of the research surrounding music in sport and exercise has examined the effects of music during exercise or activity (Karageorghis \& Terry, 1997; Lucaccini \& Kreit, 1972). However, a more recent trend of examining the effects of music as a preparation strategy has begun to receive attention in the literature (Gluch, 1993; Hall \& Erickson, 1995; Thiese \& Huddleston, 1999). Qualitative research, conducted by interviewing athletes, indicates that listening to music has become a popular strategy utilized during precompetitive preparation (Gluch, 1993; Stevens \& Lane, 2001; Thiese \& Huddleston, 1999). In an attempt to uncover how, when, and why athletes use music, Gluch (1993) interviewed six Division I athletes who reported using music as part of their precompetition routine. His results yielded several higherorder themes pertaining to the athletes' use of music.

The most commonly cited theme reported by all of the participants in Gluch’s (1993) study was the use of music for self-regulation of arousal. Music was used to either increase or decrease arousal levels as needed prior to their performances. Depending on the situational 
factors surrounding performances, the athletes reported using different selections of music based on their perceived needs (i.e., to either energize or relax). Overall, all the athletes noted that listening to music helped them feel a sense of energy that aided their psychological preparation. Consistent with Karageorghis and Terry’s (1997) conceptual framework, the athletes in Gluch’s study most commonly reported increasing their arousal level by synchronizing themselves to the beat of fast paced music. This theme of using music for self-regulation of arousal is supported by the findings of a qualitative study performed with a sample of Division I female swimmers ( $n$ =147). The swimmers completed a questionnaire rating (on a scale consisting of answers “never, " “almost never,” "almost always,” and “always”) how often they currently used each of 20 psychological skills listed. The results found "music for psych up" to be the third most commonly used skill on the list, with it being used "almost always" by the participants during their preparation (Thiese \& Huddleston, 1999).

Next, the athletes in Gluch’s (1993) study described experiencing positive emotions and attitudes while listening to music. Frequently cited emotions included feeling happy, inspired, and uplifted. The athletes reported feeling these emotions because they were able to make a connection between the songs they listened to and feelings of well-being. Similar results were found in a study by Stevens and Lane (2001) who examined the strategies used by a sample of athletes $(n=107)$ to regulate various components of their mood. Listening to music was one of the most common strategies utilized, with of the sample reporting its use to regulate the following mood factors: anger (44.86\%), confusion (20.56 \%), depression (51.40\%), fatigue (52.34 \%), tension (41.12\%), and vigor (51.40\%).

In addition, Gluch’s (1993) study also indicated that athletes mixed music with other cognitive mental preparation strategies to help facilitate their preparation. Music was combined 
with the strategies of imagery, performance cues, concentration, distraction control, and disassociation. Of these, the athletes claimed to pair music and imagery most often, allowing the athletes to visualize themselves in the upcoming performance. The relationship between their imagery and music appeared to stem from viewing performance videotapes containing music. A research study supporting this combination was conducted to examine the relationship between music, heart rate, and performance. The results showed that although performance did not increase, participants who conducted imagery with music had significantly higher heart rates than those who used imagery alone (Dorney, Goh, \& Lee, 1992). This indicates that the combination of music and imagery may serve to increase arousal prior to performance.

A last theme from Gluch’s (1993) interviews was that when the athletes used music, they reported feelings of confidence and power. Listening to music appeared to generate selfconfidence in their own abilities to the extent that they felt ready to perform well. Some of the athletes also reported drawing a sense of power (or feeling powerful) from the voice of singers and the style of music. An experimental study by Lanzillo, Burke, Joyner, \& Hardy (2001), examined the effects of listening to music during preparation for a competition on state selfconfidence. The athletes in their study $(n=59)$ were randomly assigned into two preparation conditions in which they were either asked to listen to personally chosen music at a set time in their preparation or to perform their normal preparation routine prior to the competition (i.e., scrimmage or actual game event). The results indicated that those who listened to music in their preparation had significantly higher levels of state self-confidence over those who did not listen to music $(p<.01)$. 


\section{Limitations of Music in Sport Research}

A common concern found in the music in sport literature surrounds methodological limitations that may have a significant effect on the results of research findings. In their review, Lucaccini and Kreit (1972) cite several concerns with the specific findings existing in the literature at that time. First, the inconsistent and mostly unfavorable results found in the research studies are most certainly affected by research designs that possess little experimental control. As a result, it is very difficult to distinguish the effects of music versus other confounding variables interfering with the findings. On the other hand, studies showing favorable effects of music in sport and exercise are questionable due to pervasive experimenter bias. It appears some experimenters have used methodology which could have resulted in skewed results. A second concern raised in their review regards the adequate selection of appropriate samples. Generalizations between populations of athletes and non-athletes, men and women, and blue collar and white collar workers are difficult due to the large variance in the sample populations chosen (Lucaccini \& Kreit, 1972).

More specific concerns have been expressed by Karageorghis and Terry (1997) in their review of the music in sport and exercise literature. Of major concern is the inability to control or report the specific types of music used in the research along with a lack of specific procedural instructions. These limitations make it very difficult to replicate and generalize findings across studies. Another limitation involves different types of music delivery (i.e., headphones or speakers). In terms of ecological validity, being aware of specific music listening methods is crucially important (Karageorghis \& Terry, 1997). Karageorghis and Terry also mention several time-sensitive factors that are important to the research findings. Included in this category is the duration the music is listened to and when the music is played (e.g., before or during 
performance). Last, the current research lacks the recognition of how cultural factors affect the influences of music. Again, careful consideration of the sample population is needed to ensure reliability and validity of the results.

\section{Summary}

Because sport and athletics are inherently competitive, athletes and coaches will continue to search for ways of improving performance. While there has always been an interest in refining skill development and execution to achieve this goal, a relatively new emphasis in the field of sport addresses the need to develop better preparation strategies as well. Preparation is now considered to be a very important aspect of sport that can affect performance. One of the most recent preparation strategies that has gained acceptance and popularity with coaches, athletes, and performance enhancement consultants is the use of precompetition routines. These routines are comprised of various physical and mental skills that are systematically utilized to help athletes consistently prepare for competition. Interviews with elite (i.e., Olympic) level athletes revealed that precompetition routines were viewed as a major contributing factor to the success of athletes who won medals, met expectations, or had their best matches.

Precompetition routines are theorized to serve three main purposes for the athletes that use them. First, having a routine for preparation is thought to give athletes a sense of control over their environment. This familiarization and control allows athletes to focus on their specific mental and physical preparation strategies. It is also hypothesized that precompetition routines can help limit feelings of anxiety and nervousness prior to performance. Since routines give athletes specific instructions on how to prepare, athletes may be confident that they have adequately prepared for the competition, thereby reducing anxiety. Last, the specifics of routines allocate when, where, and how athletes' time is spent during preparation. Therefore, a final 
purpose of precompetition routines is that they may limit the potential that athletes will engage in distractions that may interfere with preparation. However, these purposes regarding the effects of precompetition routines are not supported by specific research data. At this point, the literature on routines has only provided theoretical and speculative support.

A recent emphasis in literature has examined the use of music as a preparation strategy for performance that may be incorporated in precompetitive routines. Interviews with Division I athletes reveal that music is often used as a means of regulating arousal, increasing positive emotional states, enhancing cognitive preparation techniques, and eliciting feelings of confidence. However, a limited number of empirical studies have supported these subjective reports and further research is needed to clarify and examine the effects of listening to music during preparation.

Because it is perceived that listening to music has a powerful effect on human thought and behavior, music has been increasingly advocated for use in sport and exercise. Despite this suggestion, the research has failed to provide consistent data supporting the effects of music in sport. A conceptual framework has been proposed to help explain how music can have an effect within sport and exercise. First, music is thought to affect information processing such that attending to music will decrease awareness of fatigue and pain. Studies have offered support for this contention by showing that ratings of perceived exertion and fatigue were reduced by listening to music during exercise. Second, music is thought to have both an activating and relaxing effect on arousal levels depending of how the music is used. Thus far, the research in this area has produced inconsistent results. Last, people are expected to synchronize movement to the listening of music. Research has asserted positive effects in terms of endurance and energy output when listening to synchronous music as opposed to asynchronous music. 
Music has also been speculated to have an effect on mood states. Research literature supports this effect by showing that listening to music at moderate and heavy intensities resulted in more positive mood states. Further research found that listening to fast, upbeat music resulted in participants having significantly higher positive and lower negative mood states than when listening to slow or no music. These and other studies provide fairly strong evidence that music can be used to influence affective states during exercise.

Although some positive effects of music in sport and exercise have been found, overall, the body of literature examining these effects is limited and inconsistent. Common problems persist surrounding the experimental control and generalizability of the research. Lack of specificity in terms of the types of music evaluated, the intensity of music used, the duration of music listening, and the delivery of music limit the strength of the results that have been found. Inappropriate sampling procedures, as well as a failure to account for cultural and individual differences has reduced the external validity of the results. Future research is needed to establish the validity of using precompetition routines as a means of affecting the consistency of performance. In addition, more research is needed to clarify many of the discrepancies surrounding the effects of music on mood and performance. Procedures should address the limitations of previous research efforts by, (a) allowing participants to choose musical selections with personal significance or preference, (b) standardizing the delivery method of music (e.g., using headphones), and (c) varying when participants listen to the music (e.g., before or during an exercise task). Therefore, it would seem apparent that a study examining the effects of a specific precompetition routine (i.e., listening to music) on mood and performance would help to address some of the limitations of the current research on precompetition routines and music in sport. 


\section{References for Selected Review of Literature}

Billing, J. (1980). An overview of task complexity. Motor Skills: Theory into practice, 4, 18-23.

Boutcher, S. H., \& Crews, D. J. (1987). The effect of a preshot attentional routine on a welllearned skill. International Journal of Sport Psychology, 18, 30-39.

Boutcher, S. H., \& Trenske, M. (1990). The effects of sensory deprivation and music on perceived exertion and affect during exercise. Journal of Sport and Exercise Psychology, 12, $167-176$.

Brown, P. (1980). The use of music in a fitness program. CAHPER Journal, 46, 39-43.

Cohn, P. J. (1990). Preperformance routines in sport: Theoretical support and practical applications. The Sport Psychologist, 4, 301-312.

Copeland, B. L., \& Franks, B. D. (1991). Effects of types and intensities of background music on treadmill endurance. The Journal of Sports Medicine and Physical Fitness, 15, 21-33.

Davies, D. (1989). Psychological factors in competitive sport. London: The Falmer Press.

Dorney, L., Goh, E., \& Lee, C. (1992). The impact of music and imagery on physical performance and arousal: Studies of coordination and endurance. Journal of Sport Behavior, 15, 21-33.

Eklund, R. C., Gould, D., \& Jackson, S. A. (1993). Psychological foundations of Olympic wrestling excellence: Reconciling individual differences and nomothetic characterization. Journal of Applied Sport Psychology, 5, 35-47.

Fink, C., \& Taylor, J. (2002, October). The importance of routines in training and competition. Workshop presented at the annual meeting of the Association for the Advancement of Applied Sport Psychology, Tucson, Arizona. 
Gfeller, K. (1988). Musical components and styles preferred by young adults for aerobic fitness activities. Journal of Music Therapy, 25, 28-43.

Gluch, P. (1993). The use of music in preparing for sport performance. Contemporary Thought on Performance Enhancement, 2, 33-53.

Gould, D., Eklund, R. C., \& Jackson, S. A. (1992). 1988 U.S. Olympic wrestling excellence: I. Mental preparation, precompetitive cognition, and affect. The Sport Psychologist, 6, 358382.

Gould, D., Guinan, D., Greenleaf, C., Medbery, R., \& Peterson, K. (1999). Factors affecting Olympic performance: Perceptions of athletes and coaches from more and less successful teams. The Sport Psychologist, 13, 371-394.

Greenleaf, C., Gould, D., \& Diefenbach, K. (2001). Factors influencing Olympic performance: Interviews with Atlanta and Nagano U.S. Olympians. Journal of Applied Sport Psychology, 13, 154-184.

Hall, K. G., \& Erickson, B. (1995). The effects of preparatory arousal on sixty-meter dash performance. The Applied Research in Athletics and Coaching Annual, 70-79.

Hassmen, P., Koivula, N., \& Hansson, T. (1998). Precompetitive mood states and performance of elite male golfers: Do trait characteristics make a difference? Perceptual and Motor Skills, 86, 1443-1457.

Hohler, V. (1989). Sport and music. Sport Science Review, 12, 41-44.

Johnson, J., \& Siegel, D. (1987). Active vs passive attentional manipulation and multidimensional perceptions of exercise intensity. Canadian Journal of Sport Sciences, $12,41-44$. 
Karageorghis, C. I., \& Terry, P. C. (1997). The psychophysical effects of music in sport and exercise: A review. Journal of Sport Behavior, 20, 54-68.

Lanzillo, J. J., Burke, K. L., Joyner, A. B., \& Hardy, C. J. (2001). The effects of music on the intensity and direction of pre-competitive cognitive and somatic state anxiety and state self-confidence in collegiate athletes. International Sports Journal, 5, 101-110.

Losel, H. (2000). Psychoregulative effects of music. ISSF News, 40, 6-9.

Lucaccini, L. F., \& Kreit, L. H. (1972). Music. In W. P. Morgan (Ed.), Ergogenic aids and muscular performance (pp. 235-262). New York: Academic Press.

McCann, S. (1995). Developing a pre-competition plan. Olympic Coach, 5, 4-5.

Miner, M. J., Shelley, G. A., Henschen, K. P. (1995). Moving toward your potential: The athlete's guide to peak performance. Farmington, UT: Performance.

Nideffer, R. M. (1985). Athletes’ guide to mental training. Champaign, IL: Human Kinetics.

Orlick, T. (1986). Psyching for sport: Mental training for athletes. Champaign, IL: Leisure Press.

Orlick, T., \& Partington, J. (1988). Mental links to excellence. The Sport Psychologist, 2, 105130.

Prapavessis, H, \& Grove, J. R. (1994). Personality variables as antecedents of precompetitive mood states. International Journal of Sport Psychology, 25, 81-99.

Rejeski, W. J. (1985). Perceived exertion: an active or passive process? Journal of Sport Psychology, 7, 371-378.

Stevens, M. J., \& Lane, A. M. (2001, December). Mood-regulating strategies used by athletes. Athletic Insight: The online journal of sport psychology, 3. Retrieved March, 26, 2003, from http://www.athleticinsight.com/Vol3Iss3/MoodRegulation.htm. 
Taylor, J. (1995). A conceptual model for integrating athletes' needs and sport demands in the development of competitive mental preparation strategies. The Sport Psychologist, 9, 339-357.

Taylor, J., \& Wilson, G. S. (2002). Intensity regulation and sport performance. In J. L. Van Raalte \& B. W. Brewer (Eds.), Exploring sport and exercise psychology (pp. 99-130). Washington, DC: American Psychological Association.

Thiese, K. E., \& Huddleston, S. (1999). The use of psychological skills by female collegiate swimmers. Journal of Sport Behavior, 22, 602-610.

Weinberg, R. S. (1988). The mental advantage: Developing your psychological skills in tennis. Champaign, IL: Leisure Press.

Weinberg, R. S., \& Williams, J. M. (2001). Integrating and implementing a psychological skills training program. In J. M. Williams (Ed.), Applied sport psychology: Personal growth to peak performance (pp. 347-377). Mountain View, CA: Mayfield. 